\title{
Effect of Noninvasive Ventilation After Unplanned Extubation
}

\author{
Agathe Kudela, Maude Millereux, Corentin Gouezel, Dominique Prat, Frédéric Jacobs, \\ Olfa Hamzaoui, Nadège Demars, Guy Moneger, Anne Sylvie Dumenil, Pierre Trouiller, and \\ Benjamin Sztrymf
}

\begin{abstract}
BACKGROUND: Our study set out to test the effect of noninvasive ventilation (NIV) performed after unplanned extubation. METHODS: Retrospective analysis of prospectively collected data in a university-affiliated mixed ICU of 12 beds during a 5-y period (January 2013 to December 2017). Unplanned extubation was defined as the occurrence of an unplanned removal of the endotracheal tube, whether deliberate or accidental. NIV after an unplanned extubation was not protocolized and was decided by the physician in charge on an individual basis. RESULTS: A total of 121 subjects (median [25th-75th percentile] age, 62.1 [43.3-73.6] y; median [25th-75th percentile] Simplified Acute Physiology Score II, 45 [36-54]) experienced 131 unplanned extubation episodes. Re-intubation was deemed necessary in 35 subjects $(28.9 \%)$. NIV was used in 24 subjects $(19.8 \%$ ) (prophylactic NIV, $n=10$; rescue NIV, $n=14$ ). The re-intubation rates were $25.8 \%, 10 \%$, and $64.3 \%$ in the no NIV, prophylactic, and rescue NIV subgroups, respectively. The median (25th-75th percentile) time to re-intubation was longer for subjects on NIV (9.1 [3.5-49.2] vs $0.46[0.25-1] \mathrm{h}, P=.001)$. The median (25th-75th percentile) ICU length of stay and duration of mechanical ventilation were longer in the subjects who underwent NIV (14.5 [7-24.5] vs 6 [3-14] d, respectively, $P=.004$; and 9 [3-22] vs 3 [1-7.3] d, respectively, $P=.003)$. CONCLUSIONS: NIV after unplanned extubation had uncertain efficacy, especially when provided as rescue management of postextubation respiratory failure. Key words: unplanned extubation; noninvasive ventilation; re-intubation; outcome; ICU; prophylaxis. [Respir Care 2019;64(3):248-254. @ 2019 Daedalus Enterprises]
\end{abstract}

\section{Introduction}

Endotracheal intubation is frequently required during critical care patient management but harbors a number of serious complications, such as unplanned extubation. Un-

The authors are affiliated with Réanimation polyvalente et surveillance continue, Hôpital Antoine Béclère, Assistance Publique - Hôpitaux de Paris, Hôpitaux universitaires Paris Sud, Clamart, France. Dr Sztrymf is also affiliated with Institut National de la Santé et de la Recherche Médicale U999, Centre Chirurgical Marie Lannelongue, Université Paris Sud, Le Plessis Robinson, France.

The authors have disclosed no conflicts of interest.

Correspondence: Benjamin Sztrymf MD PhD, Réanimation polyvalente et surveillance continue, Hôpital Antoine Béclère, 157 rue de la porte de Trivaux, 92140 Clamart, France. E-mail: benjamin.sztrymf@aphp.fr.

DOI: $10.4187 /$ respcare. 06328 planned extubation encompasses either deliberate removal of an endotracheal tube by the patient or accidental removal during care. The incidence of unplanned extubation usually ranges from to 3 to $14 \%$ according to some studies ${ }^{1,2}$ but can be as high as $33 \%$ according to other research. ${ }^{3}$ Unplanned extubation may have severe consequences, with re-intubation required in 28.5 to $74.7 \%$ of cases. Cardiac arrhythmias, laryngeal injuries, ${ }^{4}$ nosocomial pneumonia, ${ }^{5}$ and difficult reintubation ${ }^{6}$ have been described as well, with potential lifethreatening issues. ${ }^{7,8}$ Inconsistent findings on unplanned extubation outcome exist; nevertheless, outcomes seem to mainly be driven by the need for re-intubation.2,9-11

Re-intubation after planned extubation also carries a poor prognosis and is associated with a longer ICU length of stay, ${ }^{12-14}$ need for invasive ventilation, ${ }^{12,13}$ higher ventilatorassociated pneumonia ${ }^{15,16}$ rates, and reduced survival. ${ }^{12-14}$ In the setting of planned extubation, prophylactic noninvasive ventilation (NIV) has been proven to be useful to decrease the incidence of postextubation respiratory failure and the sub- 
sequent need for re-intubations in at-risk populations. These patients are mainly represented by the elderly and patients with COPD or with chronic cardiac disability. ${ }^{17}$ Analysis of current data indicates against the use of rescue NIV in patients who experience postextubation acute respiratory failure $^{18}$ because of the risk of delayed re-intubation with the

See the Related Editorial on Page 352

subsequent prognostic consequences. Although providing NIV in a subset of patients with unplanned extubation is an interesting option, data regarding NIV in this setting are scarce and have yielded contradictory results. ${ }^{19,20}$ Recent guidelines underline the need to specifically address the use of NIV in this group of patients. ${ }^{21}$ Therefore, our main goal was to test the effect of NIV after unplanned extubation.

\section{Methods}

\section{Design and Settings}

This was a retrospective analysis of prospectively collected data. The study was conducted in a university-affiliated mixed ICU of 12 beds over a 5-y period (January 2013 to December 2017). Unplanned extubation is a frequent adverse event in the ICU, and documenting these events is recommended by both the French intensive care society (Société de Réanimation de Langue Française) and our institution's quality-related policies. Our unit follows these guidelines and routinely collects these data. Therefore, informed consent was not deemed necessary; however, the patients and their proxies were informed about the study and its goals. It is also stated on the admission leaflet of our department, which is provided to all patients and their proxies, that some variables could be anonymously registered for academic purposes.

\section{Subjects}

All adult patients (age $>18 \mathrm{y}$ ) with an endotracheal tube during their ICU stay were eligible. Unplanned extubation was defined as the occurrence of unplanned removal of the endotracheal tube, either deliberately or accidentally. A unplanned extubation may influence subsequent patient outcomes, including clinical sequelae after a second unplanned extubation; therefore, we only recorded the first such event in each subject. We excluded patients with a tracheostomy during their ICU course.

\section{Management in ICU}

A nurse-driven sedation protocol assessed by the Richmond Agitation Sedation Scale ${ }^{22}$ is used in our unit. One

\section{QUICK LOOK}

\section{Current knowledge}

Re-intubation after unplanned extubation occurs in at least $28 \%$ of patients. Extubation failure and re-intubation is associated with greater morbidity and mortality. The precise effect of noninvasive ventilation after unplanned extubation is unknown.

\section{What this paper contributes to our knowledge}

In a retrospective study, noninvasive ventilation did not improve the rate of re-intubation in subjects who harbored acute respiratory failure after unplanned extubation. Prophylactic noninvasive ventilation in this setting did not decrease the re-intubation rate.

benzodiazepine (midazolam) and an opioid agent (sufentanil) are continuously administered to reach the desired Richmond Agitation Sedation Scale score. Other agents, including common non-protocolized sedative drugs, may also have been given in specific circumstances. However, physicians and residents are asked to follow the sedation protocol as much as possible to achieve an arousal level adapted to the patient's needs. Endotracheal tubes are secured with tape by fixation to the tube and then wrapping this around the patient's neck. The patient to nurse ratio is 2.5:1.

NIV was defined as prophylactic when performed shortly after extubation before any signs of respiratory failure (prophylactic NIV). According to current evidence, our institution uses NIV in patients at high risk of postextubation respiratory failure: COPD or other chronic severe respiratory impairment, chronic cardiac failure, elderly patients, and in some patients extubated after prolonged mechanical ventilation. ${ }^{21}$ Rescue NIV was defined as the use of NIV to treat subjects with postextubation respiratory failure. The No NIV group includes subjects managed without NIV after unplanned extubation. Re-intubation was considered related to unplanned extubation up to $72 \mathrm{~h}$ after extubation. Initial NIV settings followed our unit's protocol: a pressure support of $8 \mathrm{~cm} \mathrm{H}_{2} \mathrm{O}$, PEEP of $5 \mathrm{~cm} \mathrm{H}_{2} \mathrm{O}$, inspiratory trigger of $1 \mathrm{~L} / \mathrm{min}$, and an $\mathrm{F}_{\mathrm{IO}_{2}}$ adapted to obtain a $\mathrm{S}_{\mathrm{PO}_{2}} \geq 92 \%$. These settings were then titrated, according to patient tolerance, to decrease frequency to 20 25 breaths $/ \mathrm{min}$ with a tidal volume of $6-8 \mathrm{~mL} / \mathrm{kg}$ of predicted body weight.

\section{Data}

We collected demographic data (age, baseline comorbidities), reason for ICU admission, Simplified Acute Physiology 
Score II, the time between intubation and unplanned extubation, time between ICU admission and unplanned extubation, the hour of unplanned extubation, the timing of re-intubation, duration of mechanical ventilation, ICU length of stay, and ICU survival.

\section{Statistical Analysis}

Statistical analysis was performed by using Statview 5.0 (SAS Institute, Cary, North Carolina). Continuous variables are expressed as median (25th-75th percentile) and compared by using the Mann-Whitney test. Categorical variables are expressed as number (percentage) and compared by using the Fisher exact test. A $P$ value of $<.05$ was considered statistically significant.

\section{Results}

\section{Population}

During the study period, 121 subjects experienced 131 unplanned extubation episodes, which led to an incidence of 11.4 episodes per 1,000 ventilator days. The subjects had median (25th-75th percentile) age 62.1 (43.3-73.6) y, with a median (25th-75th percentile) Simplified Acute Physiology Score II of 45 (36-54). Key characteristics of included subjects are summarized in Table 1. The main ICU admission diagnoses were hemodynamic in 14 cases (sepsis, $n=7$ ), respiratory in 40 cases (de novo acute respiratory failure, $n=24$ ), exacerbation of chronic respiratory impairment $(n=11)$, neurologic in 45 cases (toxic coma, $n=27$; seizures, $n=7$ ), postoperative in 13 cases, and miscellaneous in 9 cases (gastrointestinal bleeding, $n=7$ ) (Table 1). Re-intubation was necessary in 35 subjects (28.9\%) within $72 \mathrm{~h}$ after unplanned extubation. Three more subjects were re-intubated: one at 139, one at 274, and one at $453 \mathrm{~h}$ after unplanned extubation. Because of the delay, their re-intubation was not considered associated with unplanned extubation.

NIV after unplanned extubation was provided to 24 subjects (19.8\%), including 10 subjects for prophylactic purposes and the remaining 14 for postextubation respiratory failure (Figure 1). The reasons for re-intubation were respiratory failure $(n=30)$, shock $(n=2)$, and neurologic impairment $(n=3)$. Among the 30 subjects re-intubated for acute respiratory failure, 1 exhibited apnea, 1 had laryngeal edema, 1 experienced aspiration pneumonia, and the remaining 27 exhibited worsening oxygenation because of ongoing disease. Six subjects $(20 \%)$ required re-intubation within the first minutes after unplanned extubation. Twenty-one subjects $(70 \%)$ and 26 subjects $(86.7 \%)$ had to be re-intubated within $3 \mathrm{~h}$ and within $24 \mathrm{~h}$, respectively, after
Table 1. Description of All Subjects in Unplanned Extubation Cohort

\begin{tabular}{|c|c|}
\hline Variable & Result \\
\hline Age, median (25th-75th percentile) y & $62.1(43.3-73.6)$ \\
\hline Females/males, $n$ & $43 / 78$ \\
\hline SAPS II, median (25th-75th percentile) & $45(36-54)$ \\
\hline Chronic respiratory impairment, $n(\%)$ & $15(12.4)$ \\
\hline Chronic cardiac disease, $n(\%)$ & $5(4.1)$ \\
\hline \multicolumn{2}{|l|}{ Admission diagnosis, $n(\%)$} \\
\hline Hemodynamic & 14 (11.6) \\
\hline Respiratory & $40(33)$ \\
\hline Neurologic & $45(37.2)$ \\
\hline Postoperative & $13(10.8)$ \\
\hline Other & $9(7.4)$ \\
\hline \multicolumn{2}{|l|}{ Ventilation patterns } \\
\hline Assist-control ventilation, $n(\%)$ & $38(31.4)$ \\
\hline Pressure support, $n(\%)$ & $77(63.6)$ \\
\hline $\mathrm{SBT}, n(\%)$ & $6(5)$ \\
\hline $\mathrm{F}_{\mathrm{IO}_{2}}$, median (25th-75th percentile) $\%$ & $40(30-40)$ \\
\hline $\mathrm{V}_{\mathrm{T}}$, median (25th-75th percentile) $\mathrm{mL}$ & $450(412-526)$ \\
\hline $\begin{array}{l}\text { Breathing frequency, median (25th-75th } \\
\text { percentile) breaths/min }\end{array}$ & $20(18-25)$ \\
\hline $\mathrm{P}_{\mathrm{aO}} / \mathrm{F}_{\mathrm{IO}_{2}}$, median (25th-75th percentile) & $308(242-377)$ \\
\hline Voluntary unplanned extubation, $n(\%)$ & $101(83.5)$ \\
\hline Re-intubation, $n(\%)$ & $35(28.9)$ \\
\hline $\begin{array}{l}\text { Time between unplanned extubation and } \\
\text { re-intubation, median ( } 25 \text { th- } 75 \text { th percentile) h }\end{array}$ & $0.6(0.3-4.3)$ \\
\hline $\begin{array}{l}\text { Time on mechanical ventilation, median } \\
\text { (25th-75th percentile) } d\end{array}$ & $4(1-10.3)$ \\
\hline ICU LOS, median (25th-75th percentile) d & $7(3.5-16)$ \\
\hline Survival, $n(\%)$ & $109(90.1)$ \\
\hline \multicolumn{2}{|l|}{$\begin{array}{l}N=121 \\
\text { SAPS = Simplified Acute Physiology Score } \\
\text { SBT = spontaneous breathing trial } \\
\mathrm{V}_{\mathrm{T}}=\text { tidal volume } \\
\text { LOS = length of stay }\end{array}$} \\
\hline
\end{tabular}

unplanned extubation; the remaining subjects were reintubated 24-72 h after unplanned extubation.

There was no difference in the number of subjects who received continuous sedation at the time of unplanned extubation according to re-intubation ( $9 / 35$ vs $16 / 86$, respectively in reintubated and non reintubated patients, $P=.46$ ). Only 1 subject who underwent NIV after unplanned extubation received sedation, with no difference in the reintubation rate compared with the subjects who did not receive sedation ( $1 / 10$ vs $0 / 14$, respectively, $P=.42)$. In comparison with the subjects who did not undergo NIV, the subjects who did undergo NIV were older (median [25th-75th percentile]: 75.7 [65.7-84.3] y vs 56.7 [38.969.3] y, $P<.001$ ), were more likely to have had a chronic respiratory impairment (33.3 vs $7.2 \%, P=.008)$, more frequent respiratory disease ( 66.7 vs $23.7 \%, P=.01)$, and less frequent neurologic disease ( $8.3 \mathrm{vs} 45.4 \%, P=.02$ ) as a reason for ICU admission (Table 2). 


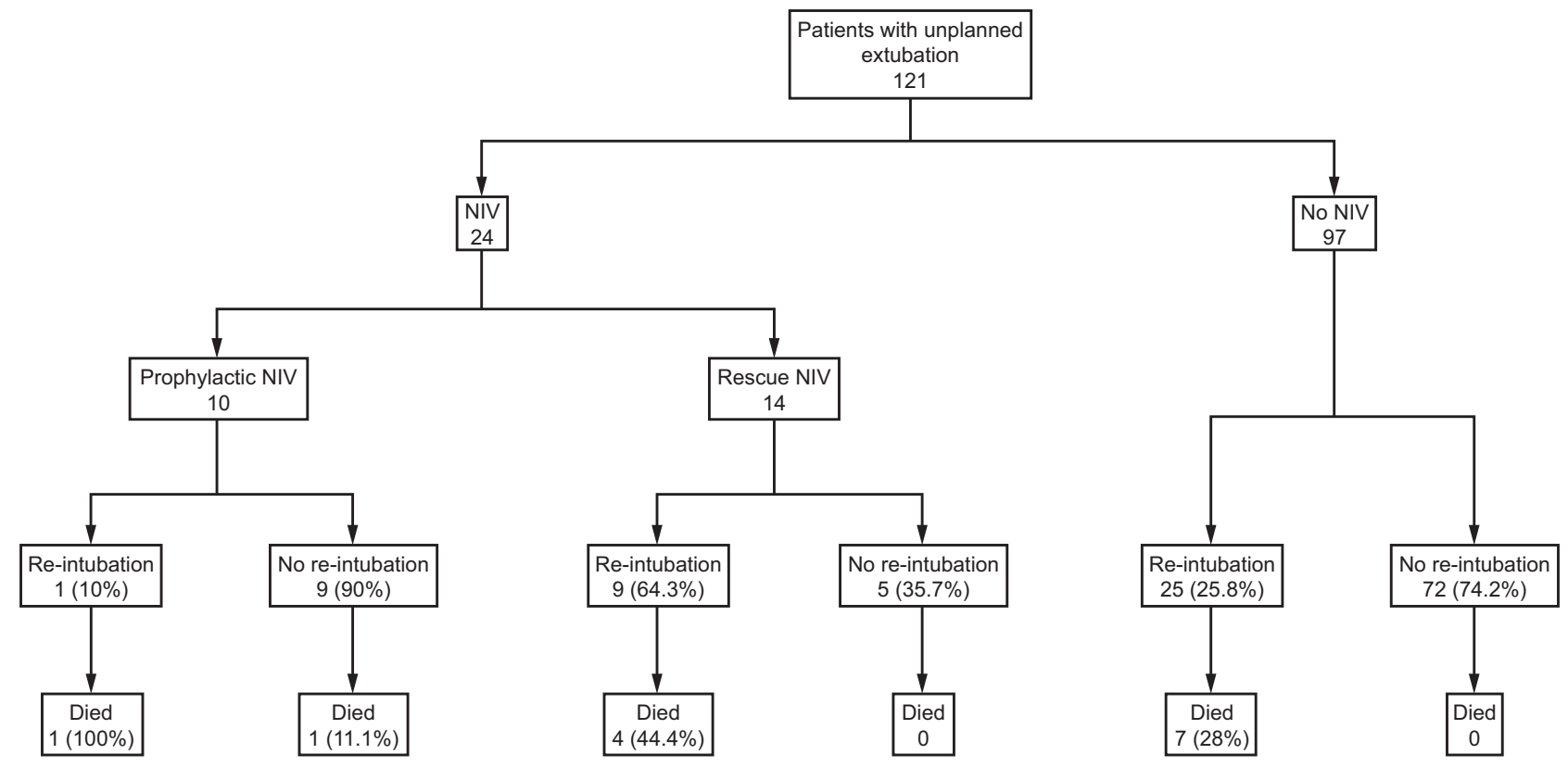

Fig. 1. Flow chart. NIV = noninvasive ventilation.

\section{Outcome According to NIV}

Overall, the re-intubation rates were $25.8 \%, 10 \%$, and $64.3 \%$ in subjects with no NIV, subjects on prophylactic NIV, and subjects on rescue NIV, respectively, which led to a non-statistically significant difference between the subjects with no NIV and all the subjects on NIV (Figure 1 and Table 2). The duration of NIV was not protocolized in the investigating center. Nevertheless, NIV sessions of $1 \mathrm{~h}$ separated by $2-4 \mathrm{~h}$ of spontaneous breathing was widely used for prophylactic NIV. With regard to rescue NIV, the durations of NIV sessions were adjusted based on signs of respiratory failure. The duration of NIV sessions in this setting ranged from $1 \mathrm{~h}$, to every $4 \mathrm{~h}$, to continuous NIV for as long as $36 \mathrm{~h}$. The time to re-intubation was longer for subjects who received NIV (median [25th-75th percentile]: 9.1 [3.5-49.2] h vs $0.46[0.25-1]$ h, $P=.001$ ). We found a trend toward a higher re-intubation rate in the rescue NIV compared with the no NIV group (64.3 vs $25.8 \%, P=.061)$, and the prophylactic NIV subgroup (64.3 vs $10 \%, P=.11$ ). As a comparison, during the study period, NIV after planned extubation was performed in 141 subjects, with 118 for prophylactic purposes and 23 as a rescue therapy. Re-intubation rates were similar between planned and unplanned extubation for prophylactic NIV $(16 / 118$ vs $1 / 10$, respectively, $P=.78)$ and rescue NIV (9/23 vs $9 / 14$, respectively, $P=.56)$.

The ICU length of stay and duration of invasive ventilation were longer in the subjects on NIV compared with the no NIV group (Table 2). This difference was mainly driven by the rescue NIV subgroup of subjects, which had a higher ICU length of stay (median [25th-75th percentile]:18.5 [14-29] d vs 6.5 [4-10] d, $P=.009$ ) and the duration of invasive ventilation (median [25th-75th percentile]: 11.5 [9-23] d vs 3 [2-5] d, $P=.009$ ) compared with the prophylactic NIV subgroup. With regard to survival, all the subjects who required re-intubation in the prophylactic NIV subgroup died as well as 4 of the 9 subjects (44.4\%) who were re-intubated after rescue NIV and 7 of the $25(28 \%)$ who were re-intubated but did not receive NIV (Figure 1). There was only one fatality among not reintubated patients, in the subgroup of "prophylactic" NIV. Altogether, there was no statistical difference in overall survival.

\section{Discussion}

The main findings of our study were as follows: (1) the subjects who required rescue NIV after unplanned extubation had a longer duration of invasive ventilation and a longer ICU length of stay, (2) prophylactic NIV after unplanned extubation was not associated with decreased reintubation rates compared with the subjects who did not undergo NIV, and (3) unplanned extubation prognosis seemed closely associated with re-intubation. Few studies report the use of NIV after unplanned extubation, without evidence of efficacy. ${ }^{19,20}$ NIV may be applied for different purposes after a planned extubation. The goals of prophylactic NIV are to reduce postextubation respiratory failure and the subsequent need for re-intubation.

Evidence for the efficacy of NIV has mainly come from patients at high risk for respiratory failure, such as those 
Table 2. Comparison Among the Subgroups

\begin{tabular}{|c|c|c|c|c|c|}
\hline \multirow[b]{2}{*}{ Variable } & \multirow{2}{*}{$\begin{array}{l}\text { No NIV } \\
(n=97)\end{array}$} & \multicolumn{3}{|c|}{ Whole Cohort } & \multirow[b]{2}{*}{$P^{*}$} \\
\hline & & $\begin{array}{l}\text { Whole Subgroup } \\
\quad(n=24)\end{array}$ & $\begin{array}{l}\text { "Prophylactic" } \\
\text { NIV }(n=10)\end{array}$ & $\begin{array}{l}\text { Rescue NIV } \\
\quad(n=14)\end{array}$ & \\
\hline Age, median (25th-75th percentile) y & $56.7(38.9-69.3)$ & $75.7(65.7-84.3)$ & $70.7(65.6-81.5)$ & $80.2(71.6-84.6)$ & $<.001$ \\
\hline Females/males, $n$ & $34 / 63$ & $9 / 15$ & $6 / 4$ & $3 / 11$ & .88 \\
\hline SAPS II, median (25th-75th percentile) & $44(35-54)$ & $47(41-53)$ & $49(45-58)$ & $46(41-54)$ & .22 \\
\hline Chronic respiratory impairment, $n(\%)$ & $7(7.2)$ & $8(33.3)$ & $3(30)$ & $5(33.3)$ & .008 \\
\hline Chronic cardiac disease, $n(\%)$ & $3(3.1)$ & $2(8.3)$ & $2(20)$ & $0(0)$ & .27 \\
\hline \multicolumn{6}{|l|}{ Admission diagnosis, $n(\%)$} \\
\hline Hemodynamic & $12(12.4)$ & $2(8.3)$ & $2(20)$ & $0(0)$ & 62 \\
\hline Respiratory & $23(23.7)$ & $16(66.7)$ & $5(50)$ & $11(78.6)$ & .01 \\
\hline Neurologic & $44(45.4)$ & $2(8.3)$ & $2(20)$ & $0(0)$ & .02 \\
\hline Postoperative & $11(11.3)$ & $3(12.5)$ & $1(10)$ & $2(14.3)$ & .89 \\
\hline Other & $7(7.2)$ & $1(4.2)$ & 0 & $1(7.1)$ & .60 \\
\hline \multicolumn{6}{|l|}{ Ventilation pattern } \\
\hline Assist-control ventilation, $n(\%)$ & $35(36.1)$ & $3(12.5)$ & $1(10)$ & $2(14.3)$ & .13 \\
\hline Pressure support, $n(\%)$ & $57(58.8)$ & $20(83.3)$ & $9(90)$ & $11(78.6)$ & .38 \\
\hline $\mathrm{SBT}, n(\%)$ & $5(5.1)$ & $1(4.2)$ & 0 & $1(7.1)$ & .85 \\
\hline $\mathrm{F}_{\mathrm{IO}_{2}}$, median (25th-75th percentile) $\%$ & $40(30-40)$ & $35(30-40)$ & $30(30-40)$ & $40(30-43)$ & .34 \\
\hline $\mathrm{V}_{\mathrm{T}}$, median (25th-75th percentile) $\mathrm{mL}$ & $450(420-500)$ & $452(385-533)$ & $430(396-474)$ & $480(378-629)$ & .89 \\
\hline $\begin{array}{l}\text { Breathing frequency, median (25th-75th } \\
\text { percentile), breaths/min }\end{array}$ & $20(18-25)$ & $20(18-26)$ & $20(18-26)$ & $21(19-25)$ & .92 \\
\hline $\mathrm{P}_{\mathrm{aO}_{2}} / \mathrm{F}_{\mathrm{IO}_{2}}$, median (25th-75th percentile) & $320(238-381)$ & $287(269-345)$ & $280(253-338)$ & $327(283-405)$ & .55 \\
\hline Voluntary unplanned extubation, $n(\%)$ & $82(84.5)$ & $22(91.7)$ & $9(90)$ & $13(92.9)$ & .87 \\
\hline Re-intubation, $n(\%)$ & $25(25.8)$ & $10(41.7)$ & $1(10)$ & $9(64.3)$ & .13 \\
\hline $\begin{array}{l}\text { Time between unplanned extubation and } \\
\text { re-intubation, median ( } 25 \text { th- } 75 \text { th percentile) } \mathrm{h}\end{array}$ & $0.46(0.25-1)$ & $9.1(3.5-49.2)$ & 29.5 & $5(3.5-49.4)$ & .001 \\
\hline $\begin{array}{l}\text { Time on mechanical ventilation, median } \\
\text { (25th-75th percentile) } d\end{array}$ & $3(1-7.3)$ & $9(3-22)$ & $3(2-5)$ & $11.5(9-23) \dagger$ & .003 \\
\hline ICU LOS, median (25th-75th percentile) d & $6(3-14)$ & $14.5(7-24.5)$ & $6.5(4-10)$ & $18.5(14-29) \dagger$ & .004 \\
\hline Survival, $n(\%)$ & $90(92.8)$ & $18(75)$ & $8(80)$ & $10(71.4)$ & .86 \\
\hline $\begin{array}{l}\text { * Comparison between No NIV group and whole NIV subgroups. } \\
\uparrow P=.009 \text { between prophylactic and rescue NIV. } \\
\text { NIV = noninvasive ventilation } \\
\text { SAPS = Simplified Acute Physiology Score } \\
\text { SBT }=\text { spontaneous breathing trial } \\
\mathrm{V}_{\mathrm{T}}=\text { tidal volume } \\
\text { LOS = length of stay }\end{array}$ & & & & & \\
\hline
\end{tabular}

with COPD. ${ }^{17} \mathrm{NIV}$ as a treatment for postextubation failure (rescue NIV) has also been evaluated. There is research that NIV might not prevent re-intubation ${ }^{23}$ and may even increase mortality by delaying the procedure. ${ }^{24}$ However, some investigators have suggested the use of rescue NIV in patients with chronic hypercapnia. ${ }^{25}$ Respiratory failure after unplanned extubation is not mentioned in our institution's NIV protocols, but physicians may deem it clinically appropriate to provide NIV in this setting. We highlight that, in our study, the time to re-intubation was longer in the subjects on NIV. As previously stated, researchers have reported that this delay may lead to adverse outcomes in patients with a planned extubation. ${ }^{24}$

Whether this is also true for patients with unplanned extubation requires further investigation. Few options exist regarding the management of respiratory failure after unplanned extubation, and re-intubation within minutes after the event is commonly reported in related studies. ${ }^{1-11}$ Therefore, we believed that NIV may have reduced re-intubation in a subset of subjects with acute respiratory failure after unplanned extubation. Also, in a substantial number of subjects in our study, NIV seemed to have been provided to prophylactically avoid postextubation respiratory failure and re-intubation. Furthermore, we do not know whether these subjects would have had a similar clinical course without the use of NIV. It is also logical to provide prophylactic NIV after unplanned extubation in patients who would have been placed on this modality after a planned extubation. Nevertheless, because of the lack of a weaning process that leads to an optimization of the patient's condition, both the benefit and safety remain to be proven. 
Altogether, although NIV could be a viable option, further data are needed to test its safety, efficacy, and precise indications after unplanned extubation. Currently, despite improvements in critical-care management, unplanned extubation is still a significant problem. Although risk factors have been identified in some cohorts, defining which patient will experience unplanned extubation on an individual basis remains challenging. Nevertheless, our study found that this event can seriously impact the patient's ICU course and lead to worse outcomes, similar to results from other studies. ${ }^{10,12}$ Our research had several limitations. First, it was a single-center study, and specificities in the pre- and postextubation care (such as sedation management or nurse-to-patient ratio) as well as discrepancies in the case mix, could limit the validity of our findings in other settings. Second, it was a retrospective study, and we may have missed eligible patients, with potential consequences on our results.

Third, we decided not to exclude subjects who experienced several unplanned extubations and to only record the first episode. We were aware that it might have impacted the ICU length of stay and other relevant clinical outcomes. However, only 5 subjects experienced $\geq 2$ unplanned extubation episodes; therefore, we believed that it was appropriate to include them. Fourth, we were aware that, despite a long study period, we included a limited number of subjects, and our sample size was further decreased by subgroup analysis. Specifically, performing only a Mann-Whitnney test between samples seemed a poor analysis to define an association between NIV and outcomes. In this kind of analysis, cofounders that were not detailed in the present study may play a huge role in the final results. We acknowledge that this might have biased the statistical analysis. Therefore, we considered our study to mainly be hypothesis-generating; the results should be confirmed with a larger cohort of subjects.

\section{Conclusions}

In this single-center, retrospective study, we found that NIV after unplanned extubation had uncertain efficacy, especially when provided as rescue management of postextubation respiratory failure. When considering the dismal outcome associated with re-intubation in this specific setting, further data are needed to define the appropriate role of NIV after unplanned extubation.

\section{REFERENCES}

1. Kapadia FN, Bajan KB, Raje KV. Airway accidents in intubated intensive care unit patients: an epidemiological study. Crit Care Med 2000;28(3):659-664.

2. Chevron V, Ménard JF, Richard JC, Girault C, Leroy J, Bonmarchand G. Unplanned extubation: risk factors of development and predictive criteria for re-intubation. Crit Care Med 1998;26(6):1049-1053.
3. Tung A, Tadimeti L, Caruana-Montaldo B, Atkins PM, Mion LC, Palmer RM, et al. The relationship of sedation to deliberate self extubation. J Clin Anesth 2001;13(1):24-29.

4. Coppolo DP, May JJ. Self-extubations: a 12-month experience. Chest 1990;98(1):165-169.

5. de Lassence A, Alberti C, Azoulay E, Le Miere E, Cheval C, Vincent F, et al; OUTCOMEREA Study Group. Impact of unplanned extubation and re-intubation after weaning on nosocomial pneumonia risk in the intensive care unit: a prospective multicenter study. Anesthesiology 2002;97(1):148-156.

6. Christie JM, Dethlefsen M, Cane RD. Unplanned endotracheal extubation in the intensive care unit. J Clin Anesth 1996;8(4):289-293.

7. Atkins PM, Mion LC, Mendelson W, Palmer RM, Slomka J, Franko T. Characteristics and outcomes of patients who self-extubate from ventilator support: a case-control study. Chest 1997;112(5):1317-1323.

8. Mort TC. Unplanned tracheal extubation outside the operating room: a quality improvement audit of hemodynamic and tracheal airway complications associated with emergency tracheal re-intubation. Anesth Analg 1998;86(6):1171-1176.

9. de Groot RI, Dekkers OM, Herold IH, de Jonge E, Arbous MS. Risk factors and outcomes after unplanned extubations on the ICU: a case-control study. Crit Care 2011;15(1):R19.

10. Krinsley JS, Barone JE. The drive to survive: unplanned extubation in the ICU. Chest 2005;128(2):560-566.

11. Lee JH, Lee HC, Jeon YT, Hwang JW, Lee H, Oh HW, Park HP. Clinical outcomes after unplanned extubation in a surgical intensive care population. World J Surg 2014;38(1):203-210.

12. Epstein SK, Ciubotaru RL, Wong JB. Effect of failed extubation on the outcome of mechanical ventilation. Chest 1997;112(1):186-192.

13. Thille AW, Harrois A, Schortgen F, Brun-Buisson C, Brochard L. Outcomes of extubation failure in medical intensive care unit patients. Crit Care Med 2011;39(12):2612-2618.

14. Esteban A, Alía I, Tobin MJ, Gil A, Gordo F, Vallverdú I, et al. Effect of spontaneous breathing trial duration on outcome of attempts to discontinue mechanical ventilation. Spanish Lung Failure Collaborative Group. Am J Respir Crit Care Med 1999;159(2):512-518.

15. Parmentier-Decrucq E, Nseir S, Makris D, Desrousseaux B, Soudan B, Favory R, Mathieu D. Accuracy of leptin serum level in diagnosing ventilator-associated pneumonia: a case-control study. Minerva Anestesiol 2014;80(1):39-47.

16. Torres A, Gatell JM, Aznar E, el-Ebiary M, Puig de la Bellacasa J, González J et al. Re-intubation increases the risk of nosocomial pneumonia in patients needing mechanical ventilation. Am J Respir Crit Care Med 1995;152(1):137-141.

17. Bajaj A, Rathor P, Sehgal V, Shetty A. Efficacy of noninvasive ventilation after planned extubation: A systematic review and metaanalysis of randomized controlled trials. Heart and Lung 2015;44(2): 150-157.

18. Lin C, Yu H, Fan H, Li Z. The efficacy of noninvasive ventilation in managing postextubation respiratory failure: a meta-analysis. Heart Lung 2014;43(2):99-104.

19. Eryüksel E, Karakurt S, Celikel T. Noninvasive positive pressure ventilation in unplanned extubation. Ann Thorac Med 2009;4(1):17-20.

20. Jiang JS, Kao SJ, Wang SN. Effect of early application of biphasic positive airway pressure on the outcome of extubation in ventilator weaning. Respirology 1999;4(2):161-165.

21. Rochwerg B, Brochard L, Elliott MW, Hess D, Hill NS, Nava S,et al. Official ERS/ATS clinical practice guidelines: noninvasive ventilation for acute respiratory failure. Eur Respir J 2017;50(2). pii: 1602426.

22. Sessler CN, Gosnell MS, Grap MJ, Brophy GM, O'Neal PV, Keane KA, et al. The Richmond Agitation-Sedation Scale: validity and reliability in adult intensive care unit patients. Am J Respir Crit Care Med 2002;166(10):1338-1344. 


\section{NIV AND UNPLANNED ExtUBATION}

23. Keenan SP, Powers C, McCormack DG, Block G. Noninvasive positive-pressure ventilation for postextubation respiratory distress: A randomized controlled trial. JAMA 2002;287(24):32383244.

24. Esteban A, Frutos-Vivar F, Ferguson ND, Arabi Y, Apezteguía C, González M, et al. Noninvasive positive-pressure ventilation for respiratory failure after extubation. N Engl J Med 2004;350(24): 2452-2460.

25. Girault C, Bubenheim M, Abroug F, Diehl JL, Elatrous S, Beuret P, et al; VENISE Trial Group. Non invasive ventilation and weaning in patients with chronic hypercapnic respiratory failure. Am J Respir Crit Care Med 2011;184(6):672-679.

This article is approved for Continuing Respiratory Care Education credit. For information and to obtain your CRCE

(free to AARC members) visit

www.rcjournal.com 